\title{
NATURALNESS IN ENGLISH: SOME (MORPHO)SYNTACTIC EXAMPLES
}

In Slovenia, the natural syntax of the Klagenfurt brand has been extended to the study of the behaviour of (near-)synonymous syntactic expressions, here called syntactic variants. The work below is illustrated with (morpho) syntactic cases from English. (Naturalness Theory applied to English has so far not received much attention.) About a half of the examples deal with relative clauses; the other half considers fronting phenomena. The language material is divided into consecutively numbered deductions, in each of which the existence of a (morpho)syntactic state of affairs is predicted on the basis of apposite assumptions and Andersen's markedness agreement rules.

\section{Introduction}

The subject-matter of this paper is a (language-universal) theory developed in Slovenia by a small group of linguists (under my guidance) that mainly use English, German, and Slovenian language material as the base of verification. Our work owes much to, and exploits, the (linguistic) Naturalness Theory as elaborated especially at some Austrian and German universities; cf. Mayerthaler (1981), Wurzel (1984), Dressler et al. (1987) and Dressler (2000). Naturalness Theory has also been applied to syntax, notably at the University of Klagenfurt; the basic references are Dotter (1990), Mayerthaler \& Fliedl (1993) and Mayerthaler et al. (1993; 1995; 1998). Within the natural syntax of the Klagenfurt brand, the Slovenian work group has built an extension that studies the behaviour of (near-)synonymous syntactic expressions, here called syntactic variants. Whenever two syntactic variants are included in the same naturalness scale, and consequently one variant can be asserted to be more natural than the other, something can be said about some grammatical properties of the two variants.

Within Naturalness Theory Mayerthaler (1981:10 et passim) distinguishes semand sym-naturalness. Because the present paper utilizes sem-naturalness only, Mayerthaler's distinction will not be discussed. Sem-naturalness will simply be called naturalness in the continuation of the paper. The predicate "natural" will be defined as simple (for the speaker) from the cognitive point of view. This kind of naturalness is similar to traditional markedness, and the following approximate equation can be stated as a first orientation of the reader: $\alpha$ markedness $=-\alpha$ naturalness. It is practically impossible to compare markedness and naturalness in (morpho)syntax seeing that the application of both in that field is in a state of flux.

Naturalness values will be stated in naturalness scales. The basic format is $>$ nat ( $A$, $B)$, i.e. with respect to cognitive complexity, $A$ is more natural than $B$. To cover any optional usage of $\mathrm{A}$ or $\mathrm{B}$, this framework assumes the following two additional formats derived from the basic format: 
(i) >nat $(\mathrm{A}+\mathrm{B}, \mathrm{B})$, i.e. with respect to cognitive complexity, optional use of $\mathrm{A}$ (with respect to $B$ ) is more natural than the use of $B$ on its own;

(ii) >nat $(A, A+B)$, i.e. with respect to cognitive complexity, the use of $A$ on its own is more natural than optional use of $B$ (with respect to $A$ ).

Any scale in one of the two derived formats (i-ii) is asserted to be true whenever the corresponding scale in the basic format >nat $(\mathrm{A}, \mathrm{B})$ is asserted to be true. Therefore, when a scale couched in a derived format is used, it suffices to back up the corresponding scale in the basic format. Given the wealth of optional usage in languages, the applicability of my framework would be greatly reduced without the two additional formats.

In the present paper, the language examples are dealt with in "deductions". Each deduction contains at least two naturalness scales. The naturalness values of paired scales will be aligned by the principle of markedness agreement as stated in Andersen 1968 (repeated in Andersen 2001), and adapted to naturalness in the following way: what is more natural tends to align with another instance of more natural; what is less natural tends to align with another instance of less natural.

Several ways of determining naturalness in (morpho)syntax feature prominently in the present paper, and deserve mention in this introduction:

(a) The principle of least effort (Havers 1931:171). What conforms better to this principle is more natural. What is cognitively simple (for the speaker) is easy to produce, easy to retrieve from memory, etc.

(b) Phylogenetic age. What is older phylogenetically is more natural. What is cognitively simpler (for the speaker) is acquired earlier by the language.

(c) Prototypicality. What is nearer to the prototype is more natural.

(d) Degree of integration into the clause. What is better integrated into its clause is more natural. This partially exploits (c): the prototypical syntactic situation is for a syntactic element to be well integrated into its syntactic construction.

(e) Frequency (in the spirit of Fenk-Oczlon 1991). What is more frequent token- and/or typewise is more natural. What is cognitively simpler (for the speaker) is used more.

(f) Small v. large class. A small class of units is more natural than a large class of units. During speech, it is easier for the speaker to choose an item from a small class than from a large class.

The following two additional ways of determining naturalness values, not used in the present paper, are mentioned to complete the picture:

(g) Specialised v. non-specialised use. The specialised use of a category is more natural than its non-specialised use. This generalisation is based on the following consideration. All kinds of categories occur in the most natural lexical items, paradigms and constructions of the language, and ebb on the way out of that core. Take a language whose noun phrases distinguish singular, plural and dual. Although sin- 
gular, plural, and dual are not equally natural with respect to each other, each of them is highly natural in its own field. For instance, the dual is highly natural (specialised) as an expression of duality: >nat (dual, singular/plural) / in expressions of duality. This is correlated with the circumstance that all the three numbers are present in personal pronouns, i.e. in the most natural noun phrases, while they may be present to different degrees in the remaining noun phrases of the language. (Recall the above-mentioned alignment rules.) For the relevant typological data about the grammatical numbers see Corbett (2000).

(h) Use v. non-use. The use of a category is more natural than its non-use. With this principle it is possible to fix the cut-off point between the use and non-use of a category. Because the use of a category normally occurs (also) with the most natural units of the relevant kind, the rules of alignment force the assumption that the use of a category is more natural than its non-use, e.g. >nat (+dual, -dual) / in expressions of duality. See the preceding item (f).

Illustrations of $(a-f)$ as well as additional ways of determining naturalness will be adduced as I proceed.

The framework just outlined will now be applied to some (morpho)syntactic variants of English. (The examples adduced below are meant to be simple and variegated.) Pairs of variants have been determined on the basis of linguistic experience. The upper limit on the length of a variant is two linked clauses. As already mentioned, each case considered is presented in the format of a deduction. The ordering of the deductions is mostly arbitrary. Section (A) considers relative clauses, and section (B) deals with fronting phenomena.

\section{(A) Relative clauses}

1.

English. In relative clauses, the pronoun whom cannot be used as a subject (Biber et al. 1999:609).

The two syntactic variants: a syntactic unit expressing any NP-relation and a syntactic unit expressing any NP-relation other than the subject.

1. The assumptions of Naturalness Theory:

1.1. >nat (who, whom) / as relativizers

I.e. the relativizer who is more natural than the relativizer whom. - Who has less sound body and internal structure than who-m. The scale abides by the principle of least effort. See item (a) in the Introduction.

1.2. >nat (subject, other NP-relations)

I.e. the subject is more natural than other NP-relations (Mayerthaler 1981:14). The subject is the prototypical NP-relation. See item (c) in the Introduction. 
A special case of 1.2:

1.2.1. >nat (subject \& other NP-relations, other NP-relations) / syntactic unit

I.e. a syntactic unit expressing any NP-relation is more natural than a syntactic unit expressing any NP-relation other than the subject. - The scale has the format $>$ nat (A $+\mathrm{B}, \mathrm{B})$. See the Introduction.

2. Markedness agreement (Andersen 2001) applied to naturalness:

2.1. $>$ nat tends to align with another $>$ nat

2.2. <nat tends to align with another <nat

The $>$ nat ( $=$ high naturalness value) of scale 1.1 is the relativizer who. It is aligned with the >nat of scale 1.2.1, which is "subject and other NP-relations". The <nat (= low naturalness value) of scale 1.1 is the relativizer whom. It is aligned with the <nat of scale 1.2.1, which is "other NP-relations".

3. The consequences:

If there is any difference between a syntactic unit expressing any NP-relation and a syntactic unit expressing any NP-relation other than the subject, such that one syntactic unit is the relativizer who, and the other syntactic unit is the relativizer whom, it is the syntactic unit expressing any NP-relation that tends to be the relativizer who, and it is the syntactic unit expressing any NP-relation other than the subject that tends to be the relativizer whom. Q.E.D.

As can be seen from the above deduction, this theoretical framework does not contain any generative component, and operates ex post facto. I cannot predict the existence of the relativizers who and whom; I cannot predict that one of these relativizers is used as any NP-relation, and that the other of these relativizers is used as any NPrelation other than the subject. However, if this data is given, it can be predicted that it is any NP-relation that is expressed by the relativizer who, and that it is any NP-relation other than the subject that is expressed by the relativizer whom. It is such predictions (that is, synchronic "accounts"/explanations) that constitute the chief motive of my work.-Mutatis mutandis, this remark applies to all deductions of the present paper.

2.

English. The zero relativizer cannot be used as the subject of the relative clause (Biber et al. 1999:609, 619-20).

The two syntactic variants: a relativizer that can assume both the zero and the nonzero form, and a relativizer that can only assume the non-zero form.

1. The assumptions of Naturalness Theory:

1.1. >nat (-relativizer, +relativizer) / subject

I.e. a subject that is not a relativizer is more natural than a subject that is a relativizer. - The prototypical subject is not a relativizer. See item (c) in the Introduction. 1.2. >nat (relativizer omission, non-omitted relativizer) 
I.e. relativizer omission is more natural than a non-omitted relativizer. - The scale abides by the principle of least effort. See item (a) in the Introduction.

A special case of 1.2:

1.2.1. >nat (+/-relativizer omission, non-omitted relativizer)

I.e. a relativizer that can be omitted is more natural than a non-omittable relativizer.-The scale has the format $>$ nat $(A+B, B)$. See the Introduction.

2. Markedness agreement (Andersen 2001) applied to naturalness:

2.1. $>$ nat tends to align with another $>$ nat

2.2. $<$ nat tends to align with another $<$ nat

3. The consequences:

If there is any difference, in relative clauses, between a relativizer that can be omitted and a non-omittable relativizer, such that one kind of relativizer is a subject, and the other kind of relativizer is not a subject, it is the non-omittable relativizer that tends to be a subject, and it is the omittable relativizer that tends not to be a subject. Q.E.D. 4. Note. Cf. deduction 8 (the relativizer that is omittable).

3.

English. The relativizer that is very rarely used with non-restrictive relative clauses (Biber et al. 1999:611).

The two syntactic variants: a relative clause admitting any relativizer, and a relative clause admitting all relativizers except that.

1. The assumptions of Naturalness Theory:

1.1. >nat (restrictive, non-restrictive) / relative clause

I.e. a restrictive relative clause is more natural than a non-restrictive relative clause (Dotter 1990:244).-Restrictive relative clauses are structurally simpler and shorter than non-restrictive relative clauses, in terms of averages. Therefore the scale abides by the principle of least effort. See item (a) in the Introduction.

1.2. >nat (that, other relativizers)

I.e. the relativizer that is more natural than other relativizers. - The relativizer that is the oldest relativizer of English. The scale is thus supported by phylogenetic considerations. See item (b) in the Introduction.

A special case of 1.2:

1.2.1. >nat (that \& other relativizers, other relativizers) / relative clause

I.e. a relative clause admitting any relativizer is more natural than a relative clause admitting all relativizers except that.-The scale has the format $>$ nat $(A+B, B)$. See the Introduction.

2. Markedness agreement (Andersen 2001) applied to naturalness:

2.1. $>$ nat tends to align with another $>$ nat

2.2. $<$ nat tends to align with another $<$ nat

3. The consequences: 
If there is any difference between a relative clause admitting any relativizer and a relative clause admitting all relativizers except that, such that one kind of relative clause is restrictive, and the other kind of relative clause is non-restrictive, it is the relative clause admitting any relativizer that tends to be restrictive, and it is the relative clause admitting all relativizers except that that tends to be non-restrictive. Q.E.D.

\section{4.}

English. Relativizers are used as subjects more often than as non-subjects (Biber et al. 1999:611, 621).

The two syntactic variants: relativizers as subjects and non-subjects.

1. The assumptions of Naturalness Theory:

1.1. >nat (+subject, -subject) / relativizable

I.e. a subject is more natural than a non-subject, as a relativizable unit. - According to the NP Accessibility Hierarchy (Croft 1990:109, with references).

1.2. >nat (more frequent, less frequent) / unit

I.e. a more frequent unit is more natural than a less frequent unit. - See item (e) in the Introduction.

2. Markedness agreement (Andersen 2001) applied to naturalness:

2.1. $>$ nat tends to align with another $>$ nat

2.2. $<$ nat tends to align with another $<$ nat

3. The consequences:

If there is any difference between relativizers that are subjects and relativizers that are not subjects, such that one kind of relativizer is common, and the other kind of relativizer is less common, it is the relativizers that are subjects that tend to be common, and it is the relativizers that are not subjects that tend to be less common. Q.E.D.

4. Note. Because the relativizers who, which, that are the only ones that can be used as subjects (Biber et al. 1999:611), they are-in conformity with item 3-the most common relativizers.

\section{5.}

English. Relativizer omission is proportionately most common in conversation (Biber et al. 1999:611).

The two syntactic variants: a relative clause admitting both relativizers and relativizer omission, and a relative clause admitting only non-omitted relativizers.

1. The assumptions of Naturalness Theory:

1.1. >nat (conversation, written registers)

I.e. conversation is more natural than written registers (Dotter 1990:228). - Written registers are clearly secondary with respect to oral communication.

1.2. >nat (relativizer omission, relativizer) / relative clause

I.e. relativizer omission is more natural than non-omitted relativizers. - The scale abides by the principle of least effort. See item (a) in the Introduction. 
A special case of 1.2:

1.2.1. >nat (relativizer \& relativizer omission, relativizer) / relative clause

I.e. a relative clause admitting both relativizers and relativizer omission is more natural than a relative clause admitting only non-omitted relativizers. - The scale has the format $>$ nat $(A+B, B)$. See the Introduction.

2. Markedness agreement (Andersen 2001) applied to naturalness:

2.1. $>$ nat tends to align with another $>$ nat

2.2. $<$ nat tends to align with another $<$ nat

3. The consequences:

If there is any difference between a relative clause admitting both relativizers and relativizer omission and a relative clause admitting only non-omitted relativizers, such that one kind of relative clause is used in conversation, and the other kind of relative clause is used in written registers, it is the relative clause admitting both relativizers and relativizer omission that tends to be used in conversation, and it is the relative clause admitting only non-omitted relativizers that tends to be used in written registers. Q.E.D.

6.

English. In conversation, relative clauses sometimes fill the gap left by the displaced relativizer with a resumptive pronoun, e.g. a thing that you don't want $\underline{i t}$. The construction is non-standard (Biber et al. 1999:622). Resumptive pronouns are not used with relativizer omission.

The two variants: relative clause showing relativizer omission, and relative clause using a non-omitted relativizer.

1. The assumptions of Naturalness Theory:

1.1. >nat (relativizer omission, non-omitted relativizer)

I.e. relativizer omission is more natural than a non-omitted relativizer. - The scale abides by the principle of least effort. See item (a) in the Introduction.

1.2. >nat (-resumptive pronoun, +resumptive pronoun) / relative clause

I.e. a relative clause lacking a resumptive pronoun is more natural than a relative clause showing a resumptive pronoun. - The scale abides by the principle of least effort. See item (a) in the Introduction.

A special case of 1.2:

1.2.1. >nat (-resumptive pronoun, $+/$-resumptive pronoun) / relative clause

I.e. a relative clause lacking a resumptive pronoun is more natural than a clause having or lacking a resumptive pronoun.-The scale has the format $>$ nat $(A, A+B)$. See the Introduction.

2. Markedness agreement (Andersen 2001) applied to naturalness:

2.1. $>$ nat tends to align with another $>$ nat

2.2. $<$ nat tends to align with another $<$ nat

3. The consequences: 
If there is any difference, in conversation, between relative clauses showing relativizer omission and relative clauses having a non-omitted relativizer, such that one kind of relative clause lacks a resumptive pronoun, and the other kind of relative clause has or lacks a resumptive pronoun, it is the relative clauses showing relativizer omission that tend to lack a resumptive pronoun, and it is the relative clauses having a nonomitted relativizer that tend to have or lack a resumptive pronoun. Q.E.D.

7.

English. Antecedents of relative clauses rarely occur in subject position. Thus the type systems which give detailed prompts appear to be very helpful is rare, whereas the type on the long incline that led to the bridge is common (Biber et al. 1999:623).

The two syntactic variants: the antecedent of the relative clause in subject position, and the antecedent of the relative clause in non-subject position.

1. The assumptions of Naturalness Theory:

1.1. >nat (subject, other NP-relations) / in nom.-acc. languages

I.e. the subject is more natural than other NP-relations, in nominative-accusative languages (Mayerthaler 1981:14). - The subject is the prototypical NP-relation. See item (c) in the Introduction.

1.2. >nat (-relative clause, +relative clause) / added to NP

I.e. an NP not expanded with a relative clause is more natural than an NP expanded with a relative clause. - The scale abides by the principle of least effort. See item (a) in the Introduction.

A special case of 1.2:

1.2.1. > nat (-relative clause, +/-relative clause) / added to NP

I.e. an NP without a relative clause is more natural than an NP with or without a relative clause. - The scale has the format $>$ nat $(A, A+B)$. See the Introduction.

2. Markedness agreement (Andersen 2001) applied to naturalness:

2.1. $>$ nat tends to align with another $>$ nat

2.2. $<$ nat tends to align with another $<$ nat

3. The consequences:

If there is any difference between the antecedent in subject position and the antecedent in non-subject position, such that one antecedent lacks a relative clause, and the other antecedent can have a relative clause, it is the antecedent in subject position that tends to lack a relative clause, and it is the antecedent in non-subject position that tends to have or lack a relative clause. Q.E.D.

8.

English. The relativizer that is elliptable, e.g. that would be the very last place that Marion and I would want to go to and what about that place we were going to stay at (Biber et al. 1999:625).

The two syntactic variants: the relativizer $w h-$, and the relativizer that. 
1. The assumptions of Naturalness Theory:

\section{1. >nat (that, wh-) / relativizer}

I.e. the relativizer that is more natural than the $w h$-relativizers. - The relativizer that is phylogenetically older than the $w h$-relativizers. See item (b) in the Introduction. 1.2. >nat (+elliptable, -elliptable) / syntactic unit

I.e. an elliptable syntactic unit is more natural than a non-elliptable syntactic unit. - Ellipsis supports the principle of least effort. See item (a) in the Introduction.

2. Markedness agreement (Andersen 2001) applied to naturalness:

2.1. $>$ nat tends to align with another $>$ nat

2.2. $<$ nat tends to align with another $<$ nat

3. The consequences:

If there is any difference between the $w h$-relativizers and the relativizer that, such that one kind is elliptable, and the other kind is not elliptable, it is the relativizer that that tends to be elliptable, and it is the $w h$-relativizers that tend not to be elliptable. Q.E.D. 4. Note. Cf. deduction 2 (the relativizer that is not omittable when acting as subject).

9.

English. The stranded preposition is elliptable in relative clauses containing the relativizer that or showing relativizer omission, e.g. that would be the very last place that Marion and I would want to go to and one place you can get a percent discount (Biber et al. 1999:624-6).

The two syntactic variants: relative clause introduced by a $w h$-relativizer and containing a stranded preposition, and relative clause introduced by the relativizer that or showing relativizer omission and containing a stranded preposition.

1. The assumptions of Naturalness Theory:

1.1. >nat (that/ $\varnothing, w h$-) / relativizer

I.e. the relativizers that/ $\varnothing$ are more natural than the $w h$ - relativizers. - The relativizers $t h a t / \varnothing$ are phylogenetically older than the relativizers $w h$-. See item (b) in the Introduction.

1.2. >nat (+elliptable, -elliptable) / stranded preposition

I.e. an elliptable stranded preposition is more natural than a non-elliptable stranded preposition. - Ellipsis supports the principle of least effort. See item (a) in the Introduction.

A special case of 1.2:

1.2.1. >nat (+elliptable, +/-elliptable) / stranded preposition

I.e. an elliptable stranded preposition is more natural than an elliptable or nonelliptable stranded preposition. - The scale has the format >nat $(A, A+B)$. See the Introduction.

3. The consequences:

If there is any difference between a $w h$ - relative clause containing a stranded preposition and a that/Ø relative clause containing a stranded preposition, such that in one 
kind of relative clause the stranded preposition can be ellipted, and in the other kind of relative clause the stranded preposition cannot be ellipted, it is in that/ $\varnothing$ relative clauses that the stranded preposition tends to be elliptable, and it is in $w h$-relative clauses that the stranded preposition tends not to be elliptable. Q.E.D.

\section{0.}

English. Adverbial relative clauses. A few head nouns corresponding to major adverbial categories-especially place, time, day, reason, and way-are particularly common for adverbial relative clauses, e.g. I can't think of a time when I would be going by myself (Biber et al. 1999:626 ff.).

The two syntactic variants: adverbial relative clauses whose antecedents are the (few) major adverbial categories, and adverbial relative clauses having other antecedents.

1. The assumptions of Naturalness Theory:

1.1. >nat (few, many) / antecedents of relative clause

I.e. a few antecedents of a relative clause are more natural than many antecedents of a relative clause. - A small class is more natural than a large class. See item (f) in the Introduction.

\section{2. >nat (more frequent, less frequent) / unit}

I.e. a more frequent unit is more natural than a less frequent unit. - See item (e) in the Introduction.

2. Markedness agreement (Andersen 2001) applied to naturalness:

2.1. $>$ nat tends to align with another $>$ nat

2.2. <nat tends to align with another $<$ nat

3. The consequences:

If there is any difference, within adverbial relative clauses, between those whose antecedents are the (few) major adverbial categories, and those having other antecedents, it is the adverbial relative clauses having the major adverbial categories as antecedents that tend to be common, and it is the adverbial relative clauses having other antecedents that tend to be less common. Q.E.D.

\section{(B) Fronting phenomena}

11.

English. Fronting of core elements is virtually restricted to declarative main clauses (discounting the initial placement of wh-words) (Biber et al. 1999:900).

The two syntactic variants: declarative main clauses and other clauses.

1. The assumptions of Naturainess Theory:

1.1. >nat (declarative main clause, other clause)

I.e. a declarative main clause is more natural than other clauses (Mayerthaler et al. 1998:326). - The declarative sentential mode is the prototypical sentential mode. Main 
clauses are phylogenetically the earliest clauses. See items (b) and (c) in the Introduction. 1.2. >nat (+core, -core) / syntactic element

I.e. a core syntactic element is more natural than a non-core syntactic element. Core syntactic elements are the prototypical clause elements. See item (c) in the Introduction.

A special case of 1.2:

1.2.1. >nat (+/-core, -core)/ syntactic element participating in fronting

I.e. fronting involving core or non-core elements is more natural than fronting involving only non-core elements. - The scale has the format $>$ nat $(A+B, B)$. See the Introduction.

2. Markedness agreement (Andersen 2001) applied to naturalness:

2.1. $>$ nat tends to align with another $>$ nat

2.2. <nat tends to align with another $<$ nat

3. The consequences:

If there is any difference between declarative main clauses and other clauses, such that in one kind of clause fronting of core elements can occur, and in the other kind of clause fronting of core elements cannot occur, it is in the declarative main clause that fronting of core elements tends to be admitted, and it is in other clauses that fronting of core elements tends not to occur. Q.E.D.

\section{2.}

English. Fronting. When a nominal or a complement clause is placed in initial position, there is no subject-verb inversion. The subject is generally a personal pronoun. The fronted element allows focus to be placed on two elements in a clause. The fronted element often contains given information. In conversation, the fronted element is mostly an object, often a demonstrative pronoun, e.g. this I do not understand (Biber et al. 1999:900, 910). The present deduction is continued in deduction 13 .

The two syntactic variants: the type I do not understand this, and the type this I do not understand.

1. The assumptions of Naturalness Theory:

1.1. >nat (-fronted, +fronted) / nominal or complement clause

I.e. a non-fronted nominal or complement clause is more natural than a fronted nominal or complement clause. - A non-fronted nominal or complement clause is better integrated into its clause than a fronted nominal or complement clause. See item (d) in the Introduction.

1.2. >nat (single focus, double focus) / clause

I.e. a clause containing single focus is more natural than a clause containing double focus.-The prototypical clause contains single focus. See item (c) in the Introduction.

2. Markedness agreement (Andersen 2001) applied to naturalness:

2.1. $>$ nat tends to align with another $>$ nat

2.2. <nat tends to align with another $<$ nat 


\section{The consequences:}

If there is any difference between the type this I do not understand and the type I do not understand this, such that one type contains double focus, and the other type contains single focus, it is the type I do not understand this that tends to contain single focus, and it is the type this I do not understand that tends to contain double focus. Q.E.D.

4. Notes.

4.1. Concerning the lack of subject-verb inversion cf. deduction 15 .

4.2. I cannot account for the fact that fronting is often motivated by the wish to place given information in clause-initial position.

\section{3.}

English. Fronting. When a nominal or a complement clause is placed in initial position, there is no subject-verb inversion. The subject is generally a personal pronoun. The fronted element allows focus to be placed on two elements in a clause. The fronted element often contains given information. In conversation, the fronted element is mostly an object, often a demonstrative pronoun, e.g. this I do not understand (Biber et al. 1999:900, 910). This deduction continues deduction 12.

The two variants: conversation and written registers.

1. The assumptions of Naturalness Theory:

\section{1. >nat (conversation, written registers)}

I.e. conversation is more natural than written registers (Dotter 1990:228). - The written registers are clearly secondary with respect to oral communication.

1.2. >nat (object, other) / core elements that can be fronted

I.e. an object is more natural than other core elements that can be fronted. - Core elements that can be fronted include objects, predicatives, infinitive predicates, etc. Among these objects are the most natural, being closest to the prototypical sentence element. See item (c) in the Introduction.

A special case of 1.2:

1.2.1. >nat (object, object \& other) / core elements that can be fronted

I.e. an object is more natural than all the core elements that can be fronted. - The scale has the format $>$ nat $(A, A+B)$. See the Introduction.

2. Markedness agreement (Andersen 2001) applied to naturalness:

2.1. >nat tends to align with another $>$ nat

2.2. <nat tends to align with another $<$ nat

3. The consequences:

If there is any difference between conversation and the written registers, such that in one kind of register objects are fronted, and in the other kind of register all core elements are fronted, it is in conversation that only objects tend to be fronted, and it is in the written registers that all core elements tend to be fronted. Q.E.D. 


\section{4.}

English. Fronting: complement clauses as fronted objects. Many examples contain a negative main clause, e.g. how he would use that knowledge he could not guess (Biber et al. 1999:901).

The two syntactic variants: main clause containing a fronted complement clause, and main clause containing a fronted nominal.

1. The assumptions of Naturalness Theory:

\section{1. >nat (nominal, clause) / object}

I.e. an object that is a nominal is more natural than an object that is a clause. - The prototypical object is a nominal. See item (c) in the Introduction.

1.2. >nat (affirmative, negative) / clause

I.e. an affirmative clause is more natural than a negative clause (Mayerthaler 1981:15).In contradistinction to negative clauses, affirmative clauses are not marked in any special way in most languages.

A special case of 1.2:

1.2.1. >nat (affirmative $\&$ negative, negative) / clause

I.e. a clause that can be affirmative or negative is more natural than a clause that can only be negative. - The scale has the format $>$ nat $(A+B, B)$. See the Introduction. 2. Markedness agreement (Andersen 2001) applied to naturalness:

2.1. $>$ nat tends to align with another $>$ nat

2.2. <nat tends to align with another $<$ nat

3. The consequences:

If there is any difference between a main clause containing a fronted nominal and a main clause containing a fronted complement clause, such that one kind of main clause can be either negative or not, and the other kind of main clause can only be negative, it is the main clause containing a fronted nominal that tends to be either negative or not, and it is the main clause containing a fronted complement clause that tends to be negative. Q.E.D.

\section{5.}

English. Fronted predicatives. Fronting of predicatives is usually accompanied by subject-verb inversion when the subject is not light in weight, e.g. far more serious were the severe head injuries. When subject-verb inversion is lacking, the subject is light in weight, namely an unstressed pronoun, e.g. right you are (Biber et al. 1999:902-904).

The two syntactic variants: fronted predicatives with and without subject-verb inversion.

1. The assumptions of Naturalness Theory:

1.1. >nat (+light, -light) / subject

I.e. a light subject is more natural than a non-light subject. - The scale abides by the principle of least effort. See item (a) in the Introduction.

1.2. >nat (SV, VS) / in SVO-languages 
I.e. the element order SV is more natural than the element order VS, in SVO-languages.

2. Markedness agreement (Andersen 2001) applied to naturalness:

2.1. $>$ nat tends to align with another $>$ nat

2.2. <nat tends to align with another $<$ nat

3. The consequences:

If there is any difference between fronted predicatives with and without subjectverb inversion, such that one order of subject and verb obtains with light subjects, and the other order of subject and verb obtains with non-light subjects, it is with light subjects that the element order SV tends to obtain, and it is with non-light subjects that the element order VS tends to obtain. Q.E.D.

16.

English. Fronting of predicatives with subject-verb order, e.g. right you are. The fronted predicative is emphatic and new information (Biber et al. 904).

The two syntactic variants: the fronted and non-fronted predicative.

1. The assumptions of Naturalness Theory:

1.1. >nat (-fronted, +fronted) / predicative

I.e. a non-fronted predicative is more natural than a fronted predicative. - A nonfronted predicative is better integrated into its clause than a fronted predicative. See item (d) in the Introduction.

1.2. >nat (given, new) / information

I.e. given information is more natural than new information. - Given information is encoded more parsimoniously than new information, in terms of averages. Thus the scale abides by the principle of least effort. See item (a) in the Introduction.

A special case of 1.2:

1.2.1. >nat (given \& new, only new) / information

I.e. containing given or new information is more natural than containing only new information. - The scale has the format $>$ nat $(\mathrm{A}+\mathrm{B}, \mathrm{B})$. See the Introduction.

1.3. >nat (-emphasis, +emphasis)

I.e. lack of emphasis is more natural than emphasis (Mayerthaler 1981:15).Emphasis is implemented only under special circumstances.

A special case of 1.3:

1.3.1. >nat (-1+emphasis, +emphasis)

I.e. optional emphasis is more natural than obligatory emphasis. - The scale has the format $>$ nat $(A+B, B)$. See the Introduction.

2. Markedness agreement (Andersen 2001) applied to naturalness:

2.1. $>$ nat tends to align with another $>$ nat

2.2. <nat tends to align with another $<$ nat

3. The consequences: 
If there is any difference between fronted and non-fronted predicatives, such that one kind of predicative conveys new information, and the other kind of predicative conveys given or new information, and such that one kind of predicative is emphatic, and the other kind of predicative is emphatic or not emphatic, it is the non-fronted predicative that tends to convey given or new information and to be or not to be emphatic, and it is the fronted predicative that tends to convey new information and to be emphatic. Q.E.D.

17.

English. Fronted infinitive predicates. There is no inversion of the subject, which is usually short. Fronted infinitive predicates often repeat a previous verb or predicate, e.g. I had said he would come down and come down he did. The fronted element is cohesive. There is a double focus in the clause (Biber et al. 1999:905-906).

The two syntactic variants: fronted and non-fronted infinitive predicates.

1. The assumptions of Naturalness Theory:

1.1. >nat (-fronted, +fronted) / infinitive predicate

I.e. a non-fronted infinitive predicate is more natural than a fronted infinitive predicate. - A non-fronted infinitive predicate is better integrated into its clause than a fronted infinitive predicate. See item (d) in the Introduction.

1.2. >nat (single focus, double focus) / clause

I.e. a clause containing single focus is more natural than a clause containing double focus. - The prototypical clause contains single focus. See item (c) in the Introduction. 2. Markedness agreement (Andersen 2001) applied to naturalness:

2.1. $>$ nat tends to align with another $>$ nat

2.2. <nat tends to align with another $<$ nat

3. The consequences:

If there is any difference between fronted and non-fronted infinitive predicates, such that clauses containing one kind of infinitive predicate have double focus, and clauses containing the other kind of infinitive predicate have single focus, it is clauses containing the non-fronted infinitive predicate that tend to have single focus, and it is clauses containing the fronted infinitive predicate that tend to have double focus. Q.E.D.

4. Notes.

4.1. Concerning subject-verb inversion cf. deduction 15 .

4.2. I cannot account for the fact that fronting is often motivated by the wish to express cohesion in clause-initial position. The repetition of the infinitive predicate is just another strategy to achieve cohesion.

4.3. Notes 4.1-2 also apply to fronted ed-and ing-predicates, e.g. enclosed is a card for our permanent signature file; standing in its cock-eyed doorway was a German colonel (cf. Biber et al. 1999:906-908). 
18.

English. Fronting of gone, e.g. gone was the vamp, the English schoolboy. The fronting of gone (and synonyms) is stylistically coloured (Biber et al. 1999:906-907).

The two syntactic variants: fronted and non-fronted gone.

1. The assumptions of Naturalness Theory:

1.1. >nat (-fronted, +fronted) / gone

I.e. a non-fronted gone is more natural than a fronted gone. - A non-fronted gone is better integrated into its clause than a fronted gone. See item (d) in the Introduction. 1.2. >nat (-stylistically marked, +stylistically marked) / syntactic element

I.e. a stylistically unmarked syntactic element is more natural than a stylistically marked syntactic element. - The stylistically marked opposite number may simply be lacking.

2. Markedness agreement (Andersen 2001) applied to naturalness:

2.1. $>$ nat tends to align with another $>$ nat

2.2. $<$ nat tends to align with another $<$ nat

3. The consequences:

If there is any difference between fronted and non-fronted gone, such that one kind of gone is stylistically marked, and the other kind not, it is the non-fronted gone that tends to be stylistically unmarked, and it is the fronted gone that tends to be stylistically marked. Q.E.D.

\section{Conclusion}

In the Consequences of each deduction, a state of affairs is predicted. What is predicted to be such-and-such a state of affairs cannot be otherwise. (In particular, the state of affairs is not likely to be the reverse of what it is.) In this sense, each state of affairs subsumed in the Consequences is accounted for ("explained" in synchronic terms).

It can likewise be seen in each deduction which assumptions couched in naturalness scales can lead to the corresponding prediction. It is the creative contribution of the linguist which scales are implemented, and in which of the three available scale formats. (In this connection, the essential fact is that the choice of the linguist's possibilities is severely limited.) It is therefore conceivable that the same prediction can be deduced from several alternative sets of assumptions. This potential has not been exploited above. 


\section{References}

ANDERSEN, Henning, "IE. *s after i, u, r, $\mathrm{k}$ in Baltic and Slavic". Acta Linguistica Hafniensia 11, 171-190. 1968.

ANDERSEN, Henning, "Markedness and the theory of linguistic change". In: Andersen (ed.) 2001, 21-57.

ANDERSEN, Henning (ed.), Actualization: Linguistic change in progress. Amsterdam: Benjamins. 2001.

BIBER, Douglas, Stig JoHANSSON, Geoffrey LEECH, Susan CONRAD \& Edward FINEGAN, Longman grammar of spoken and written English. London: Longman. 1999.

BooIJ, Geert, Christian Lehmann \& Joachim Mugdan (eds.), Morphologie: ein internationales Handbuch zur Flexion und Wortbildung, Volume I. Berlin: de Gruyter. 2000.

CoRbetT, Greville G., Number. Cambridge: Cambridge University Press. 2000.

CROFT, William, Typology and universals. Cambridge: Cambridge University Press. 1990.

DOTTER, Franz, Nichtarbitrarität und Ikonizität in der Syntax. Hamburg: Buske. 1990.

DRESSLER, Wolfgang U., Willi MAYERTHALER, Oswald PANAGL \& Wolfgang U. WURZEL, Leitmotifs in natural morphology. Amsterdam: Benjamins. 1987.

DRESSLER, Wolfgang U., "Naturalness". In: Booij et al. (eds.) 2000, 288-296.

FENK-OCZLON, Gertraud, "Frequenz und Kognition - Frequenz und Markiertheit". Folia Linguistica 25, 361-394. 1991.

HAVERS, Wilhelm, Handbuch der erklärenden Syntax. Heidelberg: Winter. 1931.

JaCoBs, Joachim, Amim von Stechow, Wolfgang StERnEFELd \& Theo VenNemann (eds.), Syntax, Volume I. Berlin: de Gruyter. 1993.

MAYERTHALER, Willi, Morphologische Natürlichkeit. Wiesbaden: Athenaion. 1981. - English version: Mayerthaler 1988.

MAYERTHALER, Willi, Morphological naturalness. Ann Arbor: Karoma. 1988.

MAYERTHALER, W. \& Günther FLIEDL, "Natürlichkeitstheoretische Syntax". In: Jacobs et al. (eds.) 1993, 610-635.

MAYERTHALER, Willi, Günther FLIEDL \& Christian WINKLER, Infinitivprominenz in europäischen Sprachen. Teil I: Die Romania (samt Baskisch). Tübingen: Narr. 1993.

MAYERTHALER, Willi, Günther FLIEDL \& Christian WINKLER, Infinitivprominenz in europäischen Sprachen. Teil II: Der Alpen-Adria-Raum als Schnittstelle von Germanisch, Romanisch und Slawisch. Tübingen: Narr. 1995.

MAYERTHALER, Willi, Günther FLIEDL \& Christian WINKLER, Lexikon der natürlichkeitstheoretischen Syntax und Morphosyntax. Tübingen: Stauffenburg. 1998.

WURZEL, Wolfgang U., Flexionsmorphologie und Natürlichkeit. Berlin: Akademie-Verlag. 1984. 


\section{Povzetek}

\section{JEZIKOVNA NARAVNOST V ANGLEŠČINI - NEKAJ (OBLIKO)SKLADENJSKIH ZGLEDOV}

V Sloveniji smo naravno skladnjo celovške šole razširili na raziskave vedenja sopomenskih in domala sopomenskih (obliko)skladenjskih izrazov, tu imenovanih skladenjske dvojnice. Naše delo je zgoraj ponazorjeno $\mathrm{z}$ (obliko)skladenjskimi zgledi iz angleščine. (Ob angleščini je teorija jezikovne naravnosti doslej doživela le malo uporabe.) Nekako polovica zgledov se tiče oziralnih odvisnikov, druga polovica pa zadeva čeljenje. Jezikovno gradivo se obravnava $\mathrm{v}$ t.i. izpeljavah. $\mathrm{V}$ vsaki izpeljavi je napovedan obstoj nekih (obliko)skladenjskih razmer, in sicer na podlagi primernih predpostavk in Andersenovih pravil o prirejanju ene vrednosti zaznamovanosti drugi taki vrednosti. 